\title{
LA IMAGINACIÓN AUTOBIOGRÁFICA APLICADA EN EL REY. DIARIO DE UN LATIN KING
}

\author{
MARIANA DEL VALLE PRADO ${ }^{1}$
}

\begin{abstract}
RESUMEN
El presente artículo analiza la aplicación práctica de las historias de vida como herramienta de investigación en la construcción de una autobiografía. En concreto, explica cómo el antropólogo catalán Carles Feixa aplicó el proceso autobiográfico, expuesto en su libro La imaginación autobiográfica. Las historias de vida como herramienta de investigación (2018), en la elaboración de la biografía de César Andrade, un joven ecuatoriano resistente en Barcelona, publicada en El Rey. Diario de un Latin King (2020). La intención de develar el método de trabajo de Feixa, docente e investigador con más de treinta años de experiencia en las historias de vidas, es aportar una caja de herramientas que pueda ser de utilidad para quienes opten por la implementación de los métodos biográficos y las fuentes orales.
\end{abstract}

PALABRAS CLAVES: HISTORIAS DE VIDA, PROCESO AUTOBIOGRÁFICO, LATIN KING

\footnotetext{
${ }^{1}$ Licenciada en Ciencias de la Comunicación por la Universidad Nacional de Tucumán (UNT), Argentina. Doctoranda del Doctorado en Humanidades por la UNT. Docente del Departamento Ciencias de la Educación de la UNT. Investigadora en Proyecto de Investigación de la UNT «Semiótica e interdisciplina: perspectivas teóricas para el análisis de procesos de sentido emergentes en Tucumán» (2018-2021), financiado por la Secretaría de Ciencia, Arte e Innovación Tecnológica (26/H606). Directora y editora de Revista Posta (ISSN 2347-014). Correo electrónico: mariana.prado@filo.unt.edu.ar
} 


\title{
A IMAginaÇão AUtOBIOGRÁfica APLICAda EM EL REY. DIÁRIO DE LATIN KING
}

\section{RESUMO}

O presente artigo analisa a aplicação prática das histórias de vida como ferramenta de pesquisa na construção de uma autobiografia. Especificamente, explica como o antropólogo catalão Carles Feixa aplicou o processo autobiográfico, exposto em seu livro La imaginación autobiográfica. Las historias de vida como herramienta de investigación (2018), na elaboração da biografia de César Andrade, um jovem equatoriano resistente em Barcelona, publicada em El Rey. Diario de uu Latin King (2020). A intenção de revelar o método de trabalho de Feixa, docente e pesquisador com mais de 30 anos de experiência nas histórias de vidas, é contribuir com uma caixa de ferramentas que possa ser útil para quem opte pela implementação dos métodos biográficos e fontes orais.

PALAVRAS-CHAVE: HISTÓRIAS DE VIDA, PROCESSO AUTOBIOGRÁFICO, LATIN

KING

\section{THE AUTOBIOGRAPHICAL IMAGINATION APPLIED TO EL REY. DIARIO DE UN LATIN KING}

\begin{abstract}
The present article analyzes the practical application of life stories as a research tool for the construction of an autobiography. Specifically explaining how Catalan anthropologist Carles Feixa applied the autobiographical process he had previously presented in his book La Imaginación Autobiografica. Las historias de vida como herramienta de investigación (2018) to develop the biography of César Andrade, a young Ecuadorian resistant in Barcelona, published in El Rey: Diario de un Latin King (2020). By revealing the work method used by Feixa, a professor and researcher with more than 30 years of experience in life stories, we intend to contribute a useful set of tools for those who choose to apply biographical methods and oral sources.
\end{abstract}

KEYWORDS: LIFE STORIES, AUTOBIOGRAPHICAL PROCESS, LATIN KING 


\section{INTRODUCCIÓN. LA CONSTRUCCIÓN DE LA HISTORIA DE VIDA}

El presente artículo analiza cómo Carles Feixa aplica la metodología propuesta en su libro La imaginación autobiográfica. Las historias de vida como herramienta de investigación en las distintas fases de la construcción de la historia de César Andrade, alias King Manaba, presentada en El Rey. Diario de un Latin King. Así pues, la revisión metodológica de esta última publicación permite reflexionar sobre la aplicación práctica del proceso autobiográfico durante algunas de las investigaciones ${ }^{2}$ que Feixa dirigió en los últimos quince años y en el marco de las cuales se realizaron las entrevistas que conforman el libro.

Los múltiples diálogos mantenidos en el transcurso de tantos años permiten dar cuenta de que la historia de vida es una herramienta metodológica que se construye en el transcurso de la investigación «mediante un proceso interactivo que implica una relación dialéctica entre varios agentes, instancias y niveles de la realidad: informante-investigador, oralidad-escritura, narraciónacción, sincronía-diacronía, memoria-historia, etcétera» (Feixa, 2018: 55). En este sentido, en coherencia con sus propuestas metodológicas, inspiradas en la «imaginación dialógica» de Mijail Bakhtin (1981), en el prólogo de El Rey, Feixa aclara que «el libro no es un monólogo del entrevistado ni una reelaboración literaria del entrevistador, sino el fruto de un diálogo entre ambos» (p. 26). Es decir, una historia de vida es una «praxis interactiva», una autobiografía que surge de una «dialéctica relacional», una narración que tienen al menos dos autores, el investigador y el entrevistado.

\footnotetext{
${ }^{2}$ Las doce entrevistas publicadas se realizaron en el marco de los siguientes proyectos de investigación: JOVLAT (2005-2008), TRESEGY (2008-2010), YOUGANG (20122013) y TRANSGANG (2018-2022).
} 


\section{SELECCIÓN DE LOS INFORMANTES}

El primer paso del proceso autobiográfico es la selección de los informantes. Feixa (2018) resalta que la muestra no responde a una voluntad de representatividad estadística, sino a un criterio de significación sociocultural: «No pretendo reflejar cuantitativamente un universo de población prefijado, sino acceder, mediante biografías singulares, a la pluralidad de los contextos históricos, sociales y culturales en los que se han desarrollado las vidas de los jóvenes» (p. 57). En este sentido, recomienda pasar de la representatividad a la significación, teniendo en cuenta que cualquier persona puede ser un buen informante, solo es necesario que tenga ganas de hablar y de compartir su historia.

En el caso de El Rey, fue el informante (César Andrade, aka King Manaba) quien se comunicó de manera voluntaria con el investigador (Carles Feixa) a raíz de lo sucedido la mañana del primer domingo de junio de 2005. Ese día, King Manaba junto a dos centenares de jóvenes de origen latinoamericano, pertenecientes a la agrupación conocida popularmente como Latin Kings, estaban por celebrar una reunión en un casal juvenil de Barcelona. Pero un centenar de policías montó un dispositivo para fichar al grupo, que vestía con ropa ancha de colores negro y amarillo.

Unas semanas antes de ese día, Feixa había intentado ponerse en contacto con los miembros de esa hermandad juvenil, solicitando una entrevista por medio de una carta que había entregado a la directora del casal con la intención de iniciar una mediación, en el marco de una investigación que dirigía sobre los jóvenes de origen latinoamericano en Barcelona. Feixa recuerda aquel día en el que se comunicó por primera vez con King Manaba de la siguiente manera:

El domingo en cuestión la directora del casal me dijo con voz temblorosa que el líder del grupo, sintiéndose acosado por el dispositivo policial, había pedido hablar conmigo. Enseguida le pasó el teléfono y escuché la voz de quien luego sabría que 
era King Manaba. Su voz parecía irritada pero firme. Me ofrecí para mediar en el conflicto, le expliqué sucintamente los objetivos de nuestro estudio y la posibilidad de contactar con las autoridades si ellos estaban de acuerdo, y quedamos al día siguiente en el casal para hablar con calma. (Feixa y Andrade, 2020: 11-12).

Así fue cómo surgió el primer contacto del investigador con el líder de la Todopoderosa Nación de Reyes y Reinas Latinos (ALKQN, por sus siglas en inglés) ${ }^{3}$, quien sería el informante principal de la investigación. Cabe destacar que desde el momento inicial, Feixa mencionó cuál era el objetivo del estudio ${ }^{4}$ que llevaba adelante por encargo de los Servicios de Prevención del Ayuntamiento. Es menester tener en cuenta este tipo de criterios éticos en la realización de las historias de vida.

A su vez, para seleccionar a los informantes, Feixa aplicó la técnica de la bola de nieve, esto es, un informante lleva a otro y este a otro, y así sucesivamente. Además, fue armando la red social del entrevistado. Por ejemplo, en la primera conversación entrevistó también a King Toro y a King Plocky, y en la tercera, a Queen Melody, a quien King Manaba había mencionado en la segunda entrevista como su pareja y madre de su hijo.

\footnotetext{
${ }^{3}$ La Todopoderosa Nación de Reyes y Reinas Latinos es una agrupación juvenil de la calle que nace en 1940 en Chicago bajo el nombre de Latin King Organization y se expande por Estados Unidos y todo el mundo. En 1954 se funda con el nombre con el que hoy se la conoce $\mathrm{y}$, paulatinamente, fueron incorporándose mujeres (reinas). Principalmente, fueron latinos e inmigrantes quienes la conformaron con el objetivo de «defender la raza, porque los latinos eran maltratados allá». Sus miembros se identifican con los colores dorado (o amarillo) y negro, que representan, respectivamente, el sol que los ilumina y el conocimiento y honor a los hermanitos difuntos. «Al unir el dorado con el negro forma la fuerza café, el linaje de nuestra raza» (Feixa y Andrade, 2020: 50). A lo largo del texto se emplean indistintamente los términos Nación (con mayúscula) y Latin King para referirse a la ALKQN.

${ }^{4}$ El objetivo de la investigación era «analizar qué había de mito y qué había de real tras la problemática de las denominadas "bandas latinas"» (Feixa y Andrade, 2020: 10).
} 
De este modo, la primera y la tercera son las únicas entrevistas en las que participan también otros informantes aparte de King Manaba. Mientras que, en varias conversaciones intervienen otros interlocutores, como el padre Joan Cabot, investigadores de los proyectos de investigación dirigidos por Feixa y estudiantes de la Universidad de Lleida y de la Universitat Pompeu Fabra.

\section{REALIZACIÓN DE LA ENTREVISTA}

El segundo paso del proceso autobiográfico es la realización de la entrevista. Es fundamental tener en cuenta que la calidad de la información que se obtiene depende, en gran medida, de la interacción establecida entre el investigador y el informante. Es decir, la entrevista «no es una técnica neutra para recoger información; es un intercambio humano entre dos personas en el que interviene la comunicación, la reciprocidad e incluso la afectividad» (Feixa, 2018: 59).

Precisamente, la autobiografía de King Manaba es fruto de múltiples conversaciones (formales e informales) mantenidas en el transcurso de quince años. Durante ese tiempo, el investigador y el informante fueron construyendo una relación antropológica basada en la confianza, el respeto, el diálogo y la empatía. También fue creciendo el afecto. En el prólogo del libro, Feixa se refiere a Manaba como amigo. A su vez, Manaba expresa en varias conversaciones que los Latin Kings consideran a Feixa como «un hermanito», «un rey», a quien bautizaron como King Book (Rey Libro).

Ahora bien, llegar a ese nivel de confianza y de aprecio implicó un arduo proceso. Al principio, los miembros de la Nación no sabían si fiarse o no de Feixa, pues sospechaban que podía ser policía o periodista. De hecho, en la primera y en la segunda entrevista, César Andrade no usó como seudónimo King Manaba sino Marco Antonio. 
Tomando como ejemplo la primera entrevista, fue un diálogo grupal (focus group), en el que además de King Manaba, participaron King Toro y King Plocky. Previamente, se negociaron una serie de condiciones. Es sumamente importante cuidar la forma en la que se desarrolla esa comunicación inicial, ya que puede potenciar o inhibir la confianza de los informantes hacia el entrevistador. Feixa (2018) explica que en la primera entrevista se precisan los objetivos de la investigación, se recogen los datos personales y se expresa el compromiso de conservar el anonimato. Por lo general, los participantes firman un consentimiento informado, en el cual se detallan, entre otros, el objetivo de la investigación y la finalidad del uso de sus datos.

La pregunta que abrió paso al relato fue de tipo general; tenía la intención de que los informantes se presentaran. Luego, Feixa preguntó: «¿Cómo se llama y en qué consiste vuestra organización?». Y a partir de ese interrogante se fue deshilvanando el hilo narrativo de esta conversación, alternando la historia del grupo con las experiencias personales.

Durante el intercambio oral, el investigador realizó distintos tipos de preguntas, que versaron entre descriptivas/explicativas («¿Cómo se implanta bandera? ¿Hay alguna ceremonia?»; «¿Cuál es la diferencia entre pandilla y nación?»; «¿Eso qué significa?»), abiertas/cerradas («¿Qué es una Nación para ustedes?»; «¿Antes habían venido otros hermanitos?») y directas/indirectas («¿Ustedes tienen gente en Madrid?»; «Antes hablaban de cuando Wolverine llegó en 2000 a Madrid...»).

Feixa (2018) recomienda dejar hablar al entrevistado y en posteriores entrevistas ir profundizando en aquellos aspectos que fueron expuestos en la primera sesión y que el investigador considera relevantes para el estudio. Así, por ejemplo, en la segunda entrevista, que en realidad fue la primera conversación biográfica de tipo formal y a solas con Manaba, le preguntó si podía contarle su vida desde el principio. De este modo, brindó la posibilidad de que el informante 
se expresara ampliamente, narrando desde su infancia en Ecuador hasta su presente en Barcelona; centrándose en el momento de su ingreso a la Nación y el de su migración a España.

Otro aspecto importante es consultar al entrevistado si es que desea hablar sobre ciertos temas y respetar su decisión. Por ejemplo, después de salir en libertad tras su primera detención y estadía en la cárcel, Feixa le preguntó a King Manaba si es que se sentía con ganas de hablar de lo que pasó y le respondió: «No, ahora no. Me abstengo. Tú sabes, Carles, que siempre he sido sincero contigo y ahora creo que no es el momento ni el sitio». En este diálogo se puede observar que la confianza, la sinceridad y, fundamentalmente, el respeto son la base de la relación que se va construyendo entre el investigador y el informante.

Feixa (2018) recomienda realizar un control de la información, contrastando con otros relatos, consultando otras fuentes. En el caso de El Rey, además de las doce conversaciones, se incluyen testimonios de personas que pertenecen a la red social de King Manaba y de autoridades de las distintas entidades gubernamentales, religiosas y civiles que apoyaron el proceso de legalización de la Organización Cultural de Reyes y Reinas Latinos de Cataluña. Algunos de estos relatos fueron recogidos de forma oral $\mathrm{y}$ otros fueron registrados de manera escrita en respuesta a un cuestionario enviado por correo electrónico. Así, por ejemplo, se reproducen palabras de sus hermanas de sangre Martha y Patricia, y los de sus hermanitos y hermanitas de la Nación: King Mission, King LP, King Kannabis, King Ghost, King Toro, King Buffalo y Queen Golden Angy. También se añaden los testimonios de Aida Quillén Lanzarote, directora del Instituto de Derechos Humanos de Catalunya; Joan Cabot, rector de la parroquia de Santa María de Lourdes; Anna Collado, directora del Casal de Jóvenes de Transformadors; Josep María Lahosa, exdirector del Servicio de Prevención del Ayuntamiento de Barcelona, y Carlos Piegari, miembro de la Federación de Entidades Latinoamericanas de Cataluña. 
Así pues, múltiples voces aportan su mirada sobre King Manaba, su narración autobiográfica es un relato polifónico y, en términos de Bakhtin (1981), heteroglósico. Esta capacidad heteroglósica surge de un doble diálogo: «El “dialogismo interno" fruto de la interacción del sujeto con su propia memoria; el “dialogismo externo" fruto de la interacción con el entorno social representado por el auditorio (o por el investigador que pregunta, transcribe e interpreta lo hablado)» (Feixa y Andrade, 2020: 32). De hecho, la narración autobiográfica inicia con «King Manaba visto por Carles Feixa» (título del prólogo) y cierra con «King Manaba visto por César Andrade» (título del epílogo), pasando por las múltiples voces que nutren el relato y quedando abierta a los nuevos diálogos que pueda suscitar su lectura.

\section{TRANSCRIPCIÓN Y ELABORACIÓN}

La tercera fase del procedimiento autobiográfico consiste en la transcripción de la entrevista y en la elaboración de la historia de vida. Sin dudas, una de las tareas más arduas es el paso del relato oral al escrito, ya que demanda una enorme cantidad de tiempo. Feixa (2018) aclara que no se trata de un trabajo meramente técnico, que pueda desvincularse del resto de la investigación, puesto que «el contexto en el que se ha desarrollado la entrevista es a menudo imprescindible para transcribir e interpretar correctamente la información que contiene» (p. 56). En este sentido, resalta que la intervención del investigador es decisiva en todo el proceso.

La mayoría de conversaciones de El Rey fueron transcritas por personas del equipo de investigación de Feixa, pero fue él quien se ha dedicado a releerlas, editarlas y adecuar la narración para su publicación. Así también, el protagonista, César Andrade, colaboró en la revisión y añadió materiales documentales.

Para la transcripción de las entrevistas se siguió el criterio de legibilidad, 
conservando la fidelidad de la fuente, ya que «transcribir una entrevista grabada no consiste tanto en reproducirla literal y escrupulosamente, sino en representarla en un nuevo medio, sin traicionar su referente original» (Feixa, 2018: 63). De este modo, se ha editado el relato del protagonista «sin perder la espontaneidad ni la riqueza del lenguaje oral, pero limitando las repeticiones o frases entrecortadas al mínimo, para no entorpecer la lectura» (Feixa y Andrade, 2020: 28).

Las palabras que en el relato oral fueron omitidas son colocadas entre corchetes. De igual modo se indica el lenguaje no verbal, por ejemplo «[risas]». Cabe destacar que se conservan los dialectos y la jerga de los informantes (escritos en cursiva). Estos términos son incluidos en un glosario al final del libro, cuyas definiciones han sido elaboradas por César Andrade y revisadas por Carles Feixa, quien recomienda pedir a los mismos entrevistados que definan esas expresiones.

Por otro lado, si bien las transcripciones de las entrevistas conservan el tono oral y la lógica interna de las conversaciones, fueron elaboradas en forma narrativa. Es decir, «se han suprimido la mayoría de las preguntas, excepto aquellas que condicionen la respuesta, que introduzcan giros en la conversación, que incluyan opiniones o informaciones relevantes, que sean diálogos a varias voces, o que incorporen preguntas de estudiantes» (p. 27). De todos modos, a pesar de haber suprimido gran cantidad de preguntas, la presencia del interlocutor en la conversación se pone de manifiesto también en ciertas frases o usos retóricos del entrevistado, como por ejemplo, «¿no?», «¿sabes?», «¿me entiendes?». Incluso, el informante menciona de manera directa al investigador: «y tú lo sabes, Carles»; «Cuando antes de conocerte a ti, ¿te acuerdas que nos reuníamos en el Casal de Transformadors?»; «Carles, yo digo una cosa y lo digo aquí a todos (...)»; «Y cuando fuiste a hablar tú, ¡bua! Ese día todo el mundo, hasta los hermanitos, me dijeron ese día: "No, si al final el que tiene que liderar a los Latin Kings es él [risas], sabe más que nosotros"». Además, se conservan 
repeticiones e intervenciones del entrevistador, «que dejan claro el origen oral de los relatos» (Feixa, 2018: 64). Por ejemplo, algunas de las acotaciones realizadas por el investigador durante las conversaciones fueron las siguientes: «lenguaje batracio, ¿no?»; «Como cualquier padre que tiene que regañar a su hijo...»; «Porque todo se basaba en escuchas telefónicas...»; «Cabeza de turco o cabeza de latino»; «Un guateque, una fiesta y el champagne, el cava también...»; «Como la película Perros callejeros»; entre otras.

\section{ANÁLISIS Y MONTAJE}

La cuarta etapa del proceso autobiográfico es el análisis y montaje. Una vez reunidas todas las transcripciones, se clasifican las conversaciones según criterios temáticos, episódicos, espaciales o biográficos. Feixa (2018) recomienda conservar la versión original de las transcripciones de las entrevistas y trabajar sobre una copia.

En El Rey, las doce entrevistas que conforman el libro (denominadas conversaciones) son presentadas cronológicamente y la mayoría se estructura en apartados temáticos o biográficos, aunque algunos momentos se repiten en varias conversaciones, por ejemplo, el día de su coronación (21 de abril de 1996): «En este caso, hemos optado por mantener íntegra la primera vez que se narra el tema, conservando las versiones posteriores, pero sintetizando aquellos pasajes que ya habían aparecido la primera vez» (Feixa y Andrade, 2020: 28).

Cada conversación está encabezada por un título y el desarrollo se organiza en subtítulos, que suelen reproducir frases del protagonista. Además, ciertas expresiones o conceptos centrales se remarcan en negrita. Las anotaciones del diario de campo de Feixa son recreadas en una suerte de epílogo que introduce cada entrevista, indicando los datos del lugar y fecha en la que se realizaron, las personas que participaron y los principales temas del diálogo. 
Las entrevistas están agrupadas en tres grandes partes en las que se organiza el libro, cuya clasificación toma elementos simbólicos de la ALKQN: sus colores (dorado, negro y café, que surge de la combinación de los dos primeros) y los estados por los que pasa un Latin King (Rey Primitivo, Rey Conservador y Nuevo Rey).

La primera parte, llamada «Dorado: El Rey Primitivo», corresponde a la fase inicial en la que el rey latino busca la luz del conocimiento y el dorado representa la realeza y las fases luminosas de su vida como Rey. Según el KMC (King's Manifesto Constitution, que define la cultura y la religión de los reyes y reinas), durante la etapa primitiva, el Rey actúa por impulso «sin pensar seriamente»y busca «darse a conocer como grande y malo». Las siete conversaciones que se incluyen narran sobre la historia y misión de la Nación, la vida de César Andrade en Ecuador, su nacimiento como King Manaba, su decisión de migrar a España, su llegada a Barcelona y el proceso de legalización de la organización en Cataluña.

La primera parte se separa de la siguiente con un pliego con fotografías de la vida de King Manaba: desde su infancia en Ecuador junto a su familia hasta su presente en Barcelona con integrantes de la Nación de diferentes naciones, con amigos, con investigadores, con King Book y con estudiantes universitarios.

La segunda parte, llamada «Negro: El Rey Conservador», corresponde al estado del Rey conservador, la fase de maduración y regresión. El color negro representa el dolor y los sacrificios de los reyes. Contiene dos conversaciones sobre la primera detención de King Manaba por delito contra la salud pública y su experiencia carcelaria desde 2009 hasta su libertad provisional en el año 2013. El pliego que separa esta parte de la siguiente incluye dos de las diez cartas que King Manaba envió a Carles Feixa durante su estancia en prisión.

La tercera parte, llamada «Café: El Nuevo Rey», corresponde al Estado del Nuevo Rey: es la etapa «del conocimiento de un sujeto autosuficiente para 
tomar decisiones» (KMC). El color café representa el mestizaje de la raza latina. En palabras de King Manaba: «Al unir el dorado con el negro forma la fuerza café, el linaje de nuestra raza» (Feixa y Andrade, 2020: 50). Contiene tres entrevistas en las que César Andrade narra sobre la segunda detención y su experiencia en prisión desde el 10 de junio de 2015 hasta el 22 de julio de 2015. Además, comenta sobre las audiencias del juicio, que se realizó durante diciembre de 2018, por organización criminal en el que King Manaba estuvo encausado (junto a otros veintidós Latin Kings) como principal imputado por ser el supuesto líder de la banda. Concluye con una valoración del momento actual en el que espera la sentencia (que finalmente llegó el 27 de enero de 2020, un día antes de enviar el libro a la imprenta, y resuelve la absolución de todos sus cargos). Esta parte culmina también con un pliego, que incluye noticias de prensa protagonizadas por King Manaba.

Luego, se presenta el epílogo, escrito por César Andrade a partir de una entrevista realizada en una clase con alumnas del Máster Universitario en Comunicación Social de la Universitat Pompeu Fabra, Barcelona.

Una serie de documentos completa la autobiografía: el glosario de los términos que surgieron en las conversaciones, tales como siglas, nombres de bandas, conceptos generales sobre grupos juveniles o sobre los Latin Kings. Se incluye también una cronología con los momentos más importantes de esta poderosa organización juvenil transnacional, como por ejemplo su origen en Estados Unidos, su refundación en América Latina y su expansión por Europa; su proceso de legalización en Cataluña y Ecuador; los problemas con la justicia; los conflictos internos con otras facciones de la asociación y los enfrentamientos con grupos rivales; los procesos de mediación; los proyectos culturales y artísticos; entre otros. 
El libro cierra con una síntesis del resultado de la sentencia del último juicio en el que César Andrade estuvo imputado y con la promesa de que esta historia «continuará».

\section{LA INTERPRETACIÓN}

La quinta etapa del proceso autobiográfico es la interpretación. En este momento se pone en relación la historia de vida con el contexto y se indaga sobre el sentido social, respondiendo, por ejemplo, a la pregunta ¿qué ha hecho esta persona para la sociedad?

El desafío del investigador es ir desde la historia particular de un sujeto a la historia social y cultural. A partir de las entrevistas, el investigador fue recopilando fechas, actores, acontecimientos, lugares, propósitos y sueños que le permiten construir una historia social. Justamente, la principal finalidad del proceso autobiográfico consiste en «leer una sociedad a través de una biografía» (Ferrarotti, 1981: 43).

Feixa ofrece tres claves de lectura para interpretar la historia de vida de King Manaba: «La historia de vida como síntesis vertical de la historia social y como síntesis horizontal de la estructura social; la historia de vida como cronotopo; la historia de vida como relato subalterno» (Feixa y Andrade, 2020: $30)$.

En el caso del relato de King Manaba, se trata de leer la sociedad contemporánea (barcelonesa, catalana, española, ecuatoriana, transnacional) a través de la biografía de un joven pandillero, iniciado como Rey primitivo en un pueblo costeño de Ecuador, emigrado a Madrid y Barcelona, donde alcanzó la categoría de inca, y que tras pasar por la cárcel en su etapa como Rey conservador, renació luego como Nuevo Rey (volviéndose algo republicano en los últimos años, por culpa de la convivencia con otra «banda», la de los investigadores e investigadoras del proyecto TRANSGANG). 
Por una parte, la historia de King Manaba puede leerse como la síntesis vertical de una historia social: la del éxodo latinoamericano a Europa (crisis en Ecuador, dolarización, emigración a España, llegada en época de vacas gordas, crisis en España, retorno voluntario versus permanencia, clandestinidad versus regularización, etc.).

Por otra parte, también puede leerse como la síntesis horizontal de una estructura social: la que origina, mantiene y persigue a las bandas como agrupaciones juveniles de calle (origen en el gueto norteamericano, refundación en América Latina como efecto de la política de deportaciones, transnacionalización hacia Europa, segregación social de la inmigración, políticas de «tolerancia cero» versus políticas «inclusivas», influencia de las representaciones mediáticas, discursos xenófobos, expansión del estado penal neoliberal, etc.). Pero lejos de ser una marioneta atrapada entre ambas coordenadas (la horizontal y la vertical), King Manaba se muestra como un actor consciente y reflexivo, capaz de enfrentarse a su destino y tomar las riendas de su vida. (Feixa y Andrade, 2020: 31-32).

Si bien el relato autobiográfico queda al acecho de la significación que cada lector y lectora pueda otorgarle, es preciso que el investigador haga explícita su interpretación de la historia de la vida, que comunique cuál es la intención del texto.

Aparte de las propuestas de lecturas realizadas por el investigador principal, es interesante también conocer las miradas que ofrecen otros participantes del proceso autobiográfico. En este caso, la de Luca Queirolo Palmas, sociólogo y profesor de la Universidad de Génova (Italia):

Manaba fue el narrador que permitió que nosotros - otros narradores - pudiésemos acompañarlo en su deseo de abrir oportunidades y reconocimiento por sujetos colocados al margen en sociedades a las que les sigue costando aceptar el derecho a la plena ciudadanía de los migrantes y sus hijos. (Feixa y Andrade, 2020: 290) 
La construcción de una historia de vida permite profundizar en el conocimiento de la dinámica sociocultural, ofreciendo un recorrido por la memoria personal y colectiva. La autobiografía de King Manaba es, al mismo tiempo, un intento de construcción, reconstrucción y deconstrucción. Por un lado, a través de la construcción de su historia de vida, se reconstruye la historia de la Almighty Latin King and Queen Nation (ALKQN) y se representa la historia de muchos y muchas jóvenes que integran esta «Nación de gente organizada». Por otro lado, se deconstruye el mito que considera a las agrupaciones juveniles de calle como «bandas criminales».

\section{LECTURA Y RESTITUCIÓN}

El trabajo con fuentes orales requiere de una etapa de retorno de los materiales a los lectores y sujetos de la investigación, «como una forma de restitución patrimonial» (Feixa, 2018: 72). En el caso de las historias de vida, se trata de una parte constitutiva, que se basa en un pacto autobiográfico entre narrador e investigador: «Sin el retorno del mensaje al emisor, el ciclo comunicativo permanece incompleto» (p. 72).

El Rey es un claro ejemplo de ese pacto autobiográfico entre narrador e investigador. El libro fue un proyecto pendiente de ambos durante mucho tiempo: «Han pasado casi 15 años desde que prometí a César Gustavo Andrade Arteaga, aka King Manaba, que escribiría un libro sobre su vida, poco después de conocerle» (Feixa y Andrade, 2020: 9). «Conjuntamente con Carles, yo siempre le he insistido en por qué no hacemos un libro de mi vida» (p. 436). La promesa finalmente se cumple y con ella, se concreta un sueño del protagonista: «Y por último, agradecerte a ti, Carles Feixa, por hacer que este sueño mío de hace quince años atrás se esté dando» (p. 454). 
El informante es coautor de su propia autobiografía, no solo la revisa y edita, sino que además redacta el epílogo a partir de una entrevista que fue transcrita, elaborada y reescrita por él. Así, el ciclo comunicativo del proceso autobiográfico se completa con la mirada en perspectiva del protagonista:

Veo que César Andrade ve a King Manaba como un Rey latino dentro de las tres etapas del rey, como el nuevo rey, como el que ha evolucionado, como el que ahora quiere ver las cosas diferentes porque ya no quiere problemas en las calles, ya no quiere problemas de ningún tipo, está enfocado solamente en su entorno familiar y amigos más cercanos, en su trabajo, en sus estudios, que es lo que realmente deberían tener y hacer todos los jóvenes. (p. 437).

Al ser la publicación fruto de un diálogo entre ambos, «la autoría y los posibles beneficios o perjuicios que deriven de ella son también compartidos» (Feixa y Andrade, 2020: 26).

\section{CONCLUSIONES}

En El Rey. Diario de un Latin King, Carles Feixa pone en práctica la propuesta metodológica de su libro La imaginación autobiográfica. Si bien su intervención es decisiva en toda la construcción de la historia de vida de César Andrade, en la publicación se limita a escribir solamente el prólogo. En él, ofrece su mirada de King Manaba, contextualiza los hechos y explicita los criterios definidos para cada etapa del proceso llevado a cabo. De este modo, el investigador primero expone su caja de herramientas y luego presenta el relato como si fuera una obra literaria.

La narración autobiográfica permite contar la vida de una persona de manera creativa, estimulando la «imaginación dialógica» (Bakhtin, 1981). «La vida de King Manaba parece una vida de película» (Feixa y Andrade, 2020: 37). 
La trama narrativa combina segmentos dramáticos, policiales, trágicos, cómicos, históricos, pedagógicos y románticos. Es un relato estimulante, que moviliza al lector, lo invita a viajar por Ecuador, dibuja paisajes de Manabí y de Santo Domingo, lo sumerge en la cultura transnacional de los reyes y reinas, lo traslada hacia Cataluña, lo lleva por terrenos pantanosos y lo hace testigo de la experiencia carcelaria.

La historia de vida de King Manaba es profunda, revela la verdad del corazón de un joven latinoamericano, nacido en un pueblo costeño y humilde de Ecuador, que luchó contra las desigualdades sociales y el abuso de poder; que cometió errores y se arrepintió; que asumió las responsabilidades de sus actos y fue víctima del mismo sistema que lo declaró victimario. El diario del rey desnuda al protagonista en cuerpo y alma: muestra sus tatuajes y expresa sus emociones, su dolor, sus sueños, sus miedos, sus pasiones, sus aciertos y sus fallas.

Cansado del acoso policial, de la estigmatización mediática y de la corrupción política en Ecuador (y en América Latina), King Manaba emprende un viaje trasatlántico al Viejo Continente en busca de una nueva vida y de conquistar sus objetivos. Pero «la vida de un emigrante es difícil» (p. 233). Desde su llegada a España tuvo que enfrentarse a la segregación social de la inmigración, a la persecución policial, a la deslealtad de sus «hermanitos», a las políticas laborales restrictivas para los inmigrantes, a la crisis de España, a los discursos mediáticos que estigmatizan a las agrupaciones juveniles y las etiquetan como «violentas»y «peligrosas».

El relato de King Manaba devela la marginación social de las juventudes, la desprotección institucional, las pujas de poder y la resistencia de la cultura subalterna. Manaba luchó con la fuerza de un guerrero y con la confianza depositada en Dios. No buscaba alcanzar la gloria individual, sino ayudar a los jóvenes: «Lo que uno hace es tal vez contar lo que uno vivió mal, transmitir un 
mensaje para que ellos no pasen lo que nosotros hemos pasado. Y pueden estar tranquilos y vivir en paz» (p. 71). «Vivir en paz en medio del caos es lo que siempre hemos querido nosotros, y siempre vamos a luchar por eso» (p. 106). «Nosotros vamos predicando las palabras de la Nación. Pero ¿qué hacemos cuando predicamos? Sacamos a los jóvenes de la calle, muchas veces los sacamos de las drogas, ése es nuestro trabajo» (p. 250).

«¡Amor de Rey!» para quien tuvo la humildad de reconocer sus errores, la sabiduría de aprender de las experiencias más dolorosas, el amor para perdonar las traiciones y el coraje para luchar por las juventudes.

FIGURA 1. Portada del libro La imaginación autobiográfica. Las historias de vida como herramienta de investigación. (Feixa, 2018)

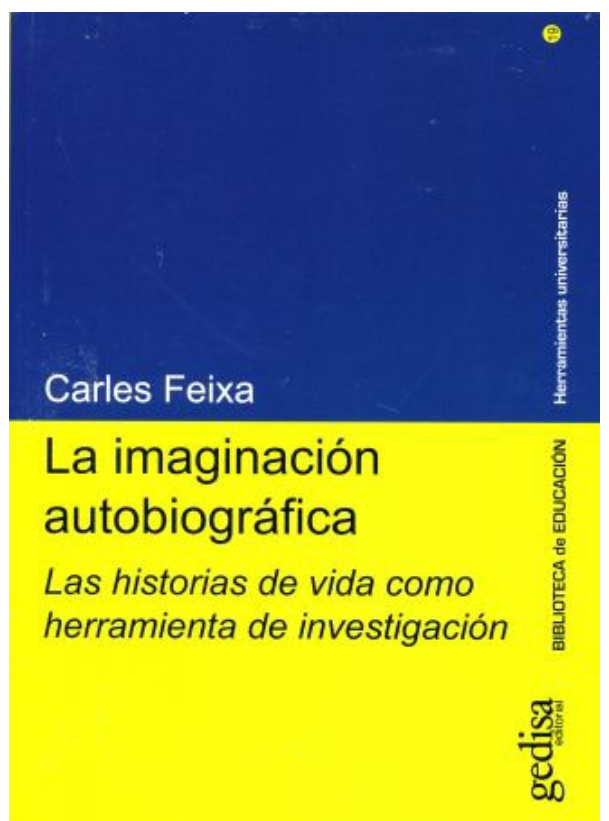

Fuente: https://www.gedisa.com/ficha.aspx?idcol=240\&cod=240019\&titulo=Laimaginaci\%c3\%b3n-autobiogr\%c3\%al fica\&aut=Feixa,\%20Carles\#.X9d9N9hKjIU 
Figura 2. Portada del libro El Rey. Diario de un Latin King. (Feixa y Andrade, 2020)

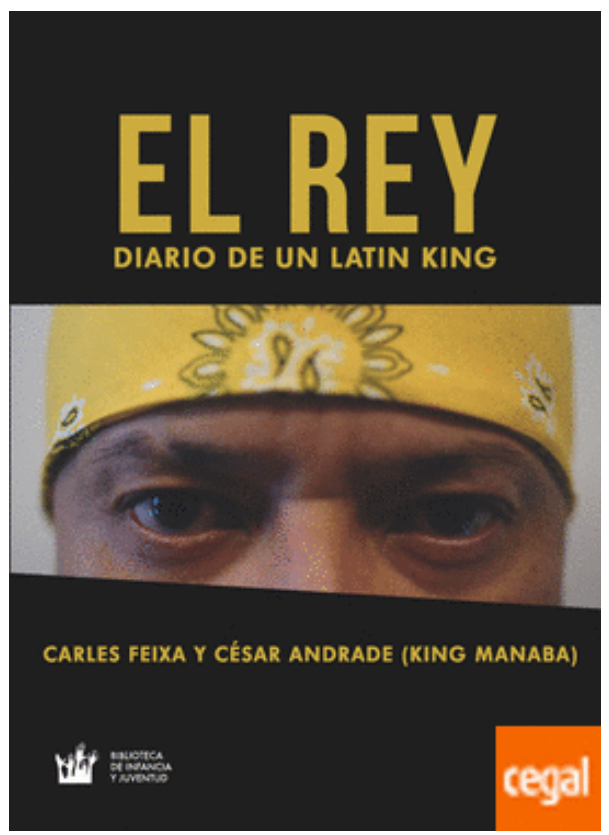

Fuente: https://www.nedediciones.com/ficha.aspx?cod=2041

FiguRA 3. Carles Feixa y César Andrade durante una entrevista realizada el 24 de octubre de 2019 en una clase con alumnas del Máster Universitario en Comunicación Social de la Universitat Pompeu Fabra, Barcelona. A partir de esta conversación, César Andrade escribió el epílogo del libro.

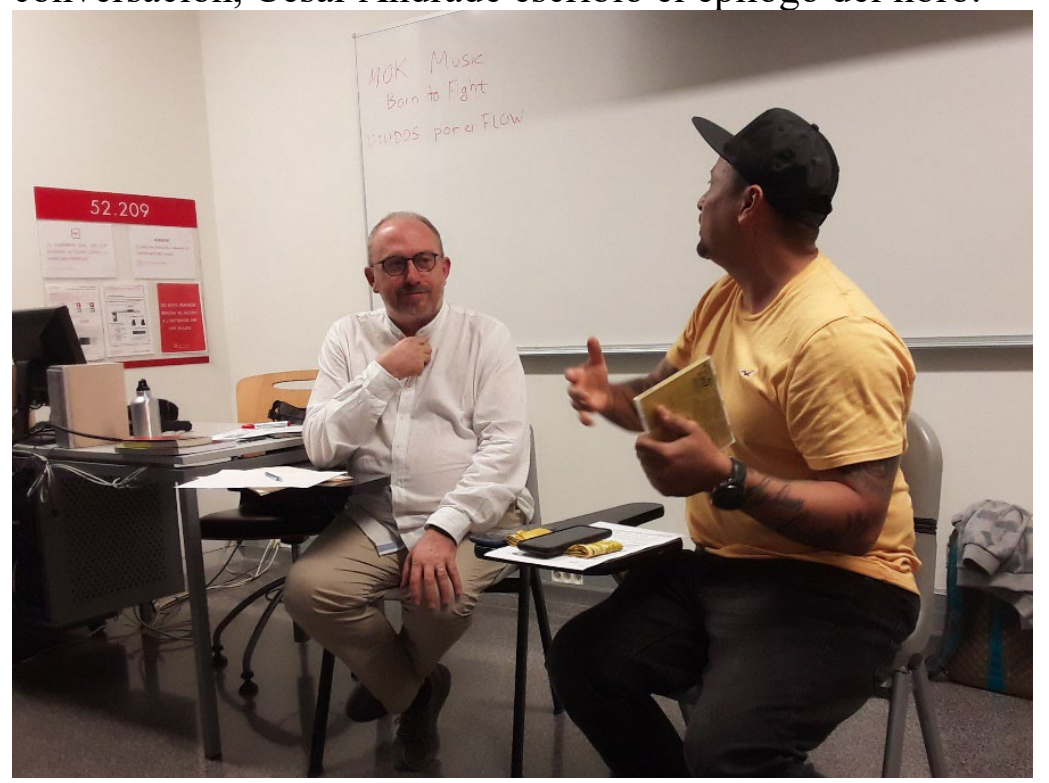

Fuente: Fotografía propia. 

El Rey. Diario de un Latin King

ENVIADO: 14 DE DICIEMBRE DE 2020 ACEPTADO: 10 DE MAYO DE 2021

\section{BIBLIOGRAFÍA}

BAKhtin, M. (1994 [1981]). The Dialogical Imagination. Austin: University of Texas Press.

Bourdieu, P. (1989). La ilusión biográfica. Historia y Fuente Oral, 2, 27-33.

FEIXA, C. (2018). La imaginación autobiográfica. Las historias de vida como herramienta de investigación. Barcelona: Gedisa.

FeiXa, C. y Andrade, C. (2020). El rey. Diario de un Latin King. Barcelona: Ned Ediciones.

FERrarotTI, F. (1981). Storia e storie di vita. Bari: Laterza.

MiLls, C. W. (1977 [1959]). La imaginación sociológica. México, D.F.: Fondo de Cultura Económica. 